\title{
O processo de formação do professor reflexivo com o uso de tecnologias digitais
}

\author{
Luciana Boff Turchielo ${ }^{1}$, Rosane Aragón ${ }^{2}$ \\ 1 Instituto Multidisciplinar - Universidade Federal Rural do Rio de Janeiro (UFRRJ), Nova \\ Iguaçu, RJ \\ 2 Faculdade de Educação - Programa de Pós-graduação em Educação (PPGEDU), \\ Universidade Federal do Rio Grande do Sul (UFRGS), Porto Alegre, RS \\ \{lucianabt14, \{rosane.aragon\} @gmail.com\}
}

\begin{abstract}
This paper discusses if the teaching and learning process, mediated by the intensive use of technologies, reached in the undergraduates, the development of practices concerning the reflective teacher theory. The objective was to investigate how the reflective formation of a group of student teachers took place in the Distance Pedagogy course. The posts published in the digital learning portfolios during the nine semesters of the training were analyzed. In the evolution of reflexive formation, the results evidenced the construction of new possibilities in the way of acting as a student and teacher. Regarding technologies, the difficulties of instrumental appropriation were overcome, in most cases, until the third semester, and its use made possible the construction of the network, as well as favoring the production of new ideas and pedagogical actions.
\end{abstract}

Resumo. Este trabalho problematiza se o processo de ensino e aprendizagem, mediado pelo uso intensivo de tecnologias alcançou nos licenciandos, o desenvolvimento de práticas acerca da teoria do professor reflexivo. O objetivo foi investigar como ocorreu a formação reflexiva de um grupo de alunas-professoras, no curso de Pedagogia a distância. Analisaram-se as postagens publicadas nos portfólios digitais de aprendizagem, no período de nove semestres da formação. Na evolução da formação reflexiva, os resultados evidenciaram a construção de novas possibilidades na forma de atuar como aluna e professora. Sobre as tecnologias, as dificuldades de apropriação instrumental foram superadas, na maioria dos casos, até o terceiro semestre, e o seu uso viabilizou a construção da rede, bem como favoreceu a produção de novas ideias e ações pedagógicas.

\section{Introdução}

O panorama da Educação Superior no país mostra que as matrículas dos cursos a distância registraram, comparativamente, um ritmo de crescimento mais acelerado: de 3,9\% (no ano de 2015, em relação a 2014); e de 20,8\% (no ano de 2015, em relação a 2013). "A título de 
comparação, em 2015, o ritmo de crescimento dos cursos presenciais foi de 2,3\% (em relação a 2014) e 7,8\% (em relação a 2013)" percentuais de expansão ou ritmo de crescimento [Brasil, 2015, p.22]. Nesse sentido, os avanços quantitativos indicam que estamos nos aproximando na correspondência do número de matrículas entre as modalidades de ensino, o que revela de maneira expressiva a importância da Educação a Distância (EAD).

Do ponto de vista da qualidade, pedagogias abertas sustentadas pelas tecnologias digitais na formação de professores em EAD possibilitam ações de uma aprendizagem em rede, pois trazem outras alternativas na estratégia de tempo e espaço com novos modos de conhecer e novas formas de pensar que se pode construir em uma comunidade de aprendizes com ação e reflexão [Nevado, Carvalho, Menezes, 2007]. Nesse modelo de formação, alunosprofessores são convidados ao exercício da reflexão crítica, autoria e a interação. Trata-se de uma proposta que visa superar a visão dicotômica que separa teoria e prática, e propõe romper com a prática prescritiva e instrumental, visando a formação do professor reflexivo. Nessa acepção, Alarcão (1996) aborda uma proposta que liga pressupostos teóricos com atividade na prática, ou dito de outra forma, propõe uma estratégia formativa de como o professor pode ser reflexivo na prática.

O presente trabalho tem como foco principal a formação de professores em contextos digitais, analisando como esta ocorre e se houve aplicabilidade de uma formação reflexiva no curso de Pedagogia, na modalidade EAD, num ambiente virtual desenvolvido a partir do conceito de Arquiteturas Pedagógicas (APs). Partindo desse objetivo, o texto está estruturado de modo a analisar e fundamentar o debate acadêmico do conceito em questão, apresentando o desenho metodológico e os resultados da análise realizada.

\section{O conceito construtivista do possível cognitivo}

A Epistemologia Genética propõe que a construção do conhecimento está ligada às atividades e ao papel ativo do sujeito. Nesse sentido, o conceito do possível cognitivo [Piaget, 1985] fornece elementos fundamentais para explicar como pensamos em algo novo ou como avançamos na extensão de conhecimentos.

Para Piaget (1985), o possível cognitivo é sempre criação-invenção de um sujeito e, em todos os processos de construção de um novo conhecimento, haverá a formação dinâmica de novos possíveis.

A formação de possíveis abarca desde uma única possibilidade até as múltiplas possibilidades de ação (física ou mental) sobre um determinado objeto. Esse processo é marcado por uma fase inicial na qual há predomínio das pseudonecessidades e das pseudoimpossibilidades (crença momentânea de que a realidade 'deve ser assim, só há um possível', enquanto a verdade se apoia em várias outras possibilidades). Assim, os problemas são colocados pelo próprio sujeito, que pode ou não permanecer por um tempo curto ou longo, até que seja ameaçado por desequilíbrios (estados de dúvidas) em razão de questionamentos das certezas iniciais e pela fragilidade nas justificativas de suas respostas [Piaget, 1985].

No decorrer do processo, o sujeito tende a superar as limitações iniciais (pseudonecessidades/pseudoimpossibilidades) diferenciando o possível e as relações necessárias entre possíveis, o que resulta na construção dos copossíveis. Nessa evolução, os copossíveis ultrapassam, gradualmente, as fronteiras do realizável concreto e imediato, 
VIII Congresso Brasileiro de Informática na Educação (CBIE 2019)

Anais dos Workshops do VIII Congresso Brasileiro de Informática na Educação (WCBIE 2019)

tornando-se, cada vez mais, abstratos e ilimitados, o que resulta na ampliação das possibilidades de ação e de compreensão do real ${ }^{1}$ pelo sujeito.

No caso desta pesquisa, foi necessário adequar o aporte teórico dos possíveis na análise dos dados empíricos, considerando que não se trata da aplicação prática da teoria, mas de uma reinterpretação dos seus pressupostos, que foram adequados às características do problema de pesquisa ${ }^{2}$.

\section{A formação do professor reflexivo e as arquiteturas pedagógicas}

A partir de suas abordagens teóricas de John Dewey e Donald Schön sobre o conceito de reflexão, Alarcão (1996) propõe, em Ser professor reflexivo, na perspectiva da formação de professores, interpretar o conceito de reflexão como um componente para o desenvolvimento pedagógico. A autora apresenta os pressupostos da operacionalização de como seria a formação do professor reflexivo na prática.

Os estudos de Zeichner e Liston (2014) e Nóvoa (2017) atualizam o debate e o entendimento desse conceito. O primeiro, sobre os tipos de ensino reflexivo e a qualidade das reflexões na formações de professores, e o segundo, no sentido de que, "[...] juntar universidades e escolas implica que umas e outras estejam dispostas a colaborar e a transformar-se, construindo processos de formação diretamente articulados com a pedagogia, a reflexão, a pesquisa, a escrita e a ação pública" [Nóvoa, 2017, p.203].

O conceito de professor reflexivo pode ser resumido na ideia do professor que faz da sua prática um objeto de reflexão teórica estruturadora de sua ação [Alarcão, 1996]. Dessa forma, o conceito tem um papel ativo como dimensão formativa do conhecimento pedagógico e consequências no modo de agir, pautando-se na ideia de um processo que envolve a reconstrução de saberes e práticas [Turchielo, 2017].

A perspectiva do modelo de comunidade de aprendizagem, ou redes de aprendizagem, é a proposta que sustenta as arquiteturas pedagógicas, na qual a aprendizagem é um processo que resulta da reorganização das ações e dos desafios vivenciados pelos sujeitos na formação a distância. Nesse modelo, os alunos são protagonistas no processo de aprendizagem [Nevado, Carvalho, Menezes, 2007]. O professor reflexivo é aquele que reflete sobre sua prática e integra novas formas de pensar e de fazer.

O que são as arquiteturas pedagógicas? Segundo Nevado, Carvalho e Menezes (2009, p.91), considera-se que são "[...] possibilidades para estruturar a aprendizagem constituídas por diferentes componentes como: abordagem pedagógica, software, Internet, inteligência artificial, educação a distância, concepção de tempo e espaço". A aplicação desse conceito, na realização de atividades reflexivas, por exemplo com o uso das APs em dinâmicas de grupo, por meio do suporte computacional, os participantes seguem regras definidas e protocolos para as trocas de mensagens que envolvem a autoria e o compartilhamento, favorecendo as interações [Junior and Reategui, 2018].

A proposta das arquiteturas pedagógicas como forma de suporte possibilita novas formas de pensar e fazer na EAD. Em termos didáticos, as tecnologias são ferramentas de comunicação que permitem a autoria usando diferentes mídias, incluindo textos, imagens,

1 Conforme definido por Piaget (1985), o real é composto de objetos e acontecimentos conhecidos ou ainda desconhecidos. Existe independente do sujeito, embora só se torne conhecido quando assimilado aos esquemas do sujeito, enquanto o possível e o necessário são produtos da própria atividade do sujeito.

${ }^{2}$ Este artigo tem como base a tese de doutoramento de Turchielo (2017) 
vídeos, e na teoria do professor reflexivo trabalha-se com questões de investigação, como: $\mathrm{O}$ que é ser aluna? O que penso sobre minha aprendizagem? O que é ser professora? O que faço na minha prática? A reflexão se inicia e será desencadeada na busca por respostas a essas perguntas. Os conhecimentos são organizados na forma de registro, com descrição, interpretação e análise que conduzem a reconstrução de saberes e práticas [Turchielo, 2017]. O desafio das perguntas pedagógicas com finalidade reflexiva possibilita, no contexto da formação, que ocorra a articulação teoria e prática.

\section{A situação de aprendizagem pesquisada: as tecnologias digitais no curso de formação a distância}

O curso de Pedagogia a distância da Universidade Federal do Rio Grande do Sul (UFRGS), primeira edição, foi escolhido como fenômeno educacional do estudo. Inicialmente delimitou-se um dos cinco polos, no caso o polo de apoio presencial do município de Alvorada (região metropolitana de Porto Alegre/RS), considerando que os sujeitos da pesquisa eram professores em escolas municipais e estaduais desse município.

As tecnologias mostraram-se fundamentais para dar suporte ao curso, considerandose o seu modelo pedagógico construtivista e interacionista. Para a mediação das comunicações e a produção de conhecimento, foram utilizados vários ambientes digitais, dentre os quais destaca-se, neste estudo, o uso do blog como suporte ao desenvolvimento dos portfólios reflexivos. Desde o início do curso, cada aluna-professora desenvolveu o seu portfólio de aprendizagem, utilizando o ambiente (http:blogger.com) na Web. A escrita deveria ser realizada semanalmente, sob a orientação de que fossem documentadas suas aprendizagens dentro e fora do curso, reflexões sobre suas práticas realizadas na escola, em resumo, reflexões sobre teoria e prática. Há de se ressaltar que o portfólio, no âmbito do curso, não se caracterizou como um repositório das melhores produções de cada alunaprofessora, e sim como uma coleção de registros que evidenciaram as trajetórias de aprendizagem durante todo o curso. O portfólio foi acompanhado e mediado pelos tutores e professores do curso, e em cada final de semestre os registros realizados foram sintetizados na produção e publicação de um texto reflexivo com foco na avaliação integrada do semestre.

\subsection{Metodologia}

O presente estudo configura-se no modelo de pesquisa guiada pelos princípios epistemológicos da investigação qualitativa. Segundo Flick (2009), a pesquisa qualitativa envolve uma postura interpretativa, na qual o pesquisador busca entender os fenômenos em termos dos sentidos que as pessoas lhes atribuem. Essa abordagem permite estudar experiências, interações e documentos em seu contexto de construção, de forma a poder considerar as suas particularidades [Flick, 2009].

O contexto da pesquisa conciliou as seguintes dimensões:

a) Sujeitos - Do contexto de 330 alunas-professoras tituladas no curso, estabeleceu-se inicialmente a escolha do polo de Alvorada titulou 61 professores. Na sequência, procedeuse aos critérios de exclusão: foram excluídos 11 sujeitos por indisponibilidade de material digital na $W e b$, e 44 sujeitos já diplomados em curso superior e/ou que não estavam em regência de classe no Ensino Fundamental. Em seguida, procedeu-se à leitura de todo o conteúdo das postagens dos seis sujeitos. Após essa fase exploratória, e devido ao grande volume de dados e informações recolhidas, optou-se pela exclusão de dois sujeitos. 
VIII Congresso Brasileiro de Informática na Educação (CBIE 2019)

Anais dos Workshops do VIII Congresso Brasileiro de Informática na Educação (WCBIE 2019)

Elegeram-se os quatro sujeitos que apresentavam material acadêmico mais adequado aos propósitos do problema de pesquisa.

b) Portfólios de aprendizagem - Os dados empíricos da pesquisa se constituíram do conteúdo dos registros textuais dos portfólios de aprendizagem (postagens) publicados nos blogs individuais de cada sujeito no âmbito da interdisciplina Seminário Integrador. Conforme Costa et al (2005), os blogs, diferentemente de outras páginas da web, são contínuos, no sentido de serem orientados a processos e não a resultados, possibilitando, assim, o registro e a expressão de uma rede de pensamentos inter-relacionados, tecida a partir das experiências pessoais.

\subsection{Categorias e procedimentos}

A partir da definição do quadro teórico de referência, elaboraram-se as categorias de análise acerca do conceito do professor reflexivo e dos níveis de reflexão, sendo os tipos das postagens em descritivas, interpretativas e reconstrutivas (nomeadas de 1-a,1-b,1-c), de acordo com Alarcão (1996). Com base no conceito construtivista do possível cognitivo de Piaget (1985), foram elaboradas as categorias de pseudonecessidades ou pseudoimpossibilidades, copossíveis, possíveis (nomeadas de 2-a, 2-b, 2-c). Na última categoria, foram identificados os conteúdos/temas específicos nas postagens em relação às tecnologias (3-a). O Quadro I apresenta os códigos, categorias e descritores para a análise hierárquica das semelhanças.

Quadro 1: Códigos, categorias e descritores utilizados no curso

\begin{tabular}{|c|c|c|}
\hline Código & Categorias & Descritores \\
\hline $1-\mathbf{a}$ & Descritiva & $\begin{array}{l}\text { A postagem descreve eventos que o sujeito percebe e/ou elege como } \\
\text { importantes, podendo ou não ser feita através do recurso da narrativa. }\end{array}$ \\
\hline $1-b$ & Interpretativa & $\begin{array}{l}\text { A postagem da aluna-professora atribui significado teórico para suas } \\
\text { aprendizagens no curso e/ou questiona os desafios de sua prática na } \\
\text { escola. }\end{array}$ \\
\hline $1-c$ & Reconstrutivas & $\begin{array}{l}\text { A postagem menciona reflexões sobre práticas orientadas pelo curso, } \\
\text { práticas reconstruídas com a introdução de novos elementos. }\end{array}$ \\
\hline 2-a & $\begin{array}{l}\text { Pseudonecessidades } \\
\text { ou pseudo- } \\
\text { impossibilidades }\end{array}$ & $\begin{array}{l}\text { Refere-se ao ponto de vista do sujeito (diferente do pesquisador) que } \\
\text { acredita que algo é necessário ou impossível de ser pensado ou } \\
\text { realizado, mas na realidade não é [(Piaget,1985]. }\end{array}$ \\
\hline $2-b$ & Copossíveis & $\begin{array}{l}\text { Refere-se às ideias (hipóteses) que o sujeito em tentativas de } \\
\text { interpretar, realiza variações no conteúdo e/ou ação, buscando } \\
\text { alcançar uma generalização e/ou construir uma reflexão [Piaget, } \\
\text { 1985]. }\end{array}$ \\
\hline $2-c$ & Possíveis & $\begin{array}{l}\text { Refere-se à capacidade cognitiva do sujeito de atualizar ideias e ações } \\
\text { nos processos de construção de novos conhecimentos e práticas } \\
\text { [Piaget, 1985]. }\end{array}$ \\
\hline 3-a & Tecnologias & $\begin{array}{l}\text { O conteúdo da postagem traz menções sobre o uso, dificuldades e } \\
\text { conquistas nos diferentes ambientes virtuais de aprendizagem } \\
\text { (ambiente ROODA, blog, pbworks) e, de modo geral, no uso das } \\
\text { tecnologias digitais. }\end{array}$ \\
\hline
\end{tabular}


Na sequência, com objetivo de integrar as análises, foram elaboradas planilhas no formato Excel com a totalidade dos dados do estudo, referentes aos atributos dos $1^{\circ}$ ao $3^{\circ}$ semestre (momento I), dos $4^{\circ}$ ao $6^{\circ}$ semestre (momento II), dos $7^{\circ}$ ao $9^{\circ}$ semestre (momento III). Esse processo de categorização originou uma matriz contendo a presença de cada categoria, e a seguir essa matriz foi submetida ao software Classification Hiérarchique Implicative et Cohésitive (CHIC). Essas informações, no tratamento da análise hierárquica de semelhanças do software CHIC, geraram os grafos (árvores das similaridades), que apresentaram as relações de similaridade ou coerência, levando em conta critérios de similaridade e de coesão entre as variáveis. Essa análise consiste em um método de organização de variáveis, segundo sua intersecção, e estabelece como critério de semelhança a "vizinhança" ou associação. O valor máximo dos níveis de similaridade é igual a 1 [Grás, 1992].

\section{Análise e resultados}

A análise a seguir apresenta as associações entre as categorias, resultantes do tratamento hierárquico das semelhanças, de modo a evidenciar como ocorreram os processos de formação, na perspectiva do professor reflexivo. O nó mais significativo está no nível 1, e analisaram-se os nós significativos que estão entre o nível 1 ao 4 , com maior índice de similaridade.

\subsection{Análise do momento I ( $\left(1^{\circ}\right.$ ao $3{ }^{\circ}$ semestre $)$}

Os relatórios do CHIC indicam duas relações de implicações mais fortes destacadas com a linha vermelha. A figura abaixo apresenta a árvore de similaridade do início $\left(1^{\mathrm{o}}\right.$ ao $3^{\mathrm{o}}$ semestre) do curso.

Abaixo a tabela dos índices que formam a árvore de similaridades do $1^{\circ}$ ao $3^{\circ}$ semestre, elaborado a partir do relatório do CHIC.
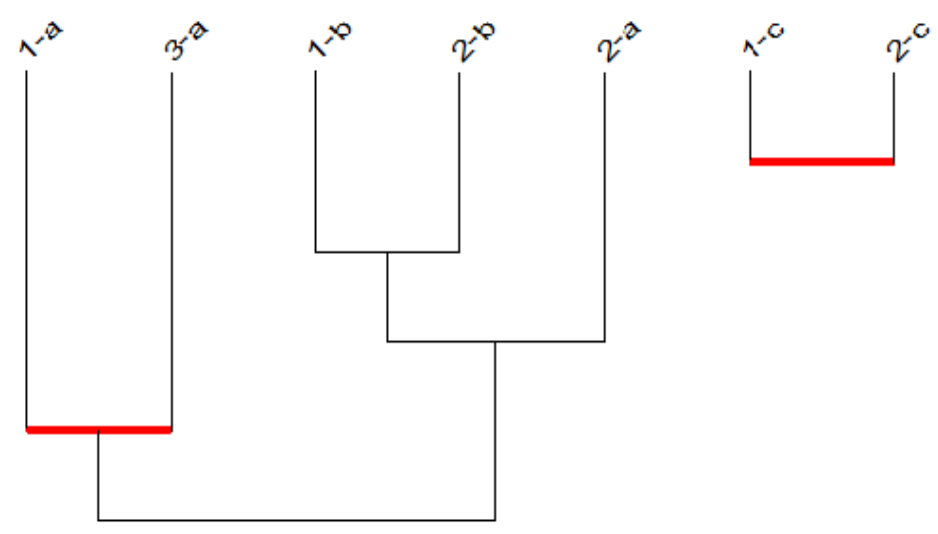

Figura 1. Árvore de similaridades do início do curso.

Nível: 1: (1-c 2-c) similaridade: 1

Nível: 2: (1-b 2-b) similaridade: 0.999922

Nível: 3: ((1-b 2-b) 2-a) similaridade: 0.999068

Nível: 4: (1-a 3-a) similaridade: 0.86019 
Dentre as relações e convergências, no início do curso, é significativa a relação entre as postagens descritivas com conteúdo que relatam assuntos pessoais (expectativas em relação ao curso) e sentimentos (1-a) e o uso das tecnologias (3-a). Nesse caso, as dificuldades de apropriação tecnológica, referenciadas pelas alunas-professoras, principalmente no início do curso, contribuem para o entendimento dessa relação. Outra explicação é que a falta de familiaridade com as tecnologias demandaria mais tempo para o uso instrumental, uma vez que o sujeito fica em tentativas de ensaios e erros ou num estado de indiferenciação, no qual não consegue avançar para uma etapa seguinte. Nesse caso, necessita buscar ajuda do outro, dos tutores ou de pessoas próximas. Trata-se da ideia de que era preciso primeiro dominar o uso das tecnologias para depois escrever a reflexão sobre a sua aprendizagem.

Nesse primeiro momento, o pensamento reflexivo apresenta-se diretamente ligado aos conteúdos que as alunas-professoras citam quando estão narrando ou interpretando suas descobertas e aprendizagens. Tal fato evidencia um início da formação de redes de aprendizagem no curso que demandam trocas entre os sujeitos (colegas, tutores e professores formadores).

As convergências entre as postagens reconstrutivas (1c) e as postagens que evidenciaram evoluções na capacidade reflexiva (2c), quando ocorreram, nos sugere que as alunas-professoras passavam a realizar postagens reconstrutivas conforme ocorria uma evolução na sua capacidade reflexiva. Essa relação sugere que a autoestima das alunas aumentava na medida em que elas evoluíam academicamente no curso e nas conquistas e possibilidades como o uso das tecnologias.

\subsection{Análise do momento II ( $4^{\circ}$ ao $6^{\circ}$ semestre)}

Observa-se que as relações evidenciadas nesta árvore de similaridades do período da metade dos estudos no curso estão representadas em duas unidades separadas, com dois destaques de relações fortes. A Figura 2 apresenta a árvore e os índices de similaridade do $4^{\circ}$ ao $6^{\circ}$ semestre, elaborado a partir do relatório do CHIC.

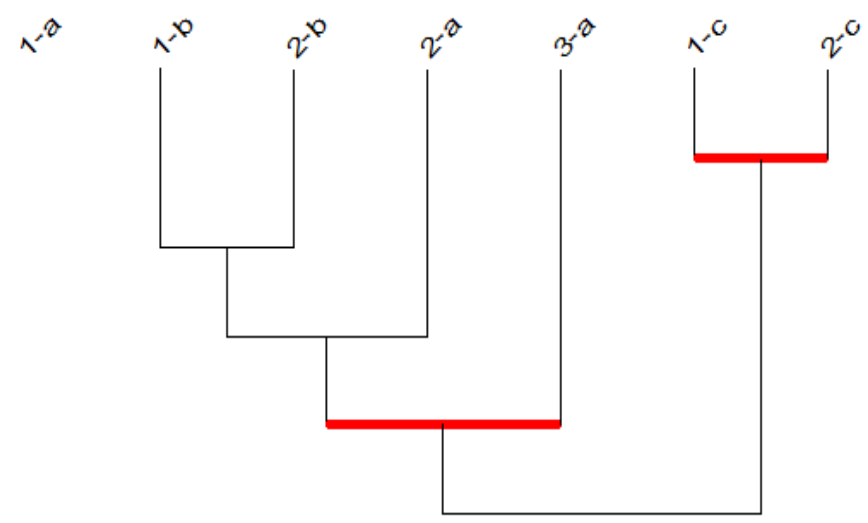

Figura 2. Árvore de similaridades da metade do curso.

Nível: 1: (1-c 2-c) similaridade: 1

Nível: 2: (1-b 2-b) similaridade: 0.999422

Nível: 3: ((1-b 2-b) 2-a) similaridade: 0.67792 
O primeiro 'ramo' do grafo mostra a ligação entre as relações de similaridade entre as postagens reconstrutivas (1-c) e a formação de possíveis (2-c), que podem ser explicadas como a atualização de possibilidades de novas articulações entre teoria e prática (copossíveis) que se multiplicam na evolução do curso e são confirmadas, seguindo a tendência do início do curso apresentada na figura 1. A exceção foi a diminuição das postagens descritivas (1a), não ligando-se com as demais.

A classe do 'ramo' que liga o nível 2 refere-se às relações significativas de similaridade entre as postagens interpretativas (1-b) e a formação de copossíveis (2-b) que podem ser identificadas nos entrelaçamentos das temáticas nesse período do curso, e evidenciam como os sujeitos buscavam estabelecer relações entre as aprendizagens e as transformações nas suas concepções.

A partir do II momento ( $4^{\circ}$ semestre em diante), as alunas-professoras mostraram que estavam superadas as dificuldades instrumentais com o uso das tecnologias. As postagens sobre o uso das tecnologias mencionavam os recursos utilizados e suas possibilidades. $\mathrm{O}$ nível 3 indica que as interpretações dos sujeitos trazem conteúdos reflexivos sobre sua aprendizagem no curso e prática na escola. Essas relações mostram a relevância da arquitetura de projetos (realizados com o uso das tecnologias) para as aprendizagens das alunas-professoras nesse período intermediário do curso. Tal resultado confirma que "[...] as arquiteturas propõem deslocamentos que visam dar às tecnologias sentidos que ultrapassem o seu uso periférico e dissociado das práticas pedagógicas, ressignificando os papéis e as formas de mediação, bem como oferecendo condições "estruturantes" para as construções coletivas" [Aragón, Charczuk e Ziede 2016, p. 571]

\subsection{Análise do momento III ( $7^{\circ}$ ao $9^{\circ}$ semestre)}

Os resultados da árvore de similaridade dos três últimos semestres estão representados em duas unidades separadas, com dois destaques de relações significativas, permanecendo a mesma tendência da análise do primeiro momento. Na Figura 3, é apresentada a tabela dos índices de similaridades do $7^{\circ}$ ao $9^{\circ}$ semestre.
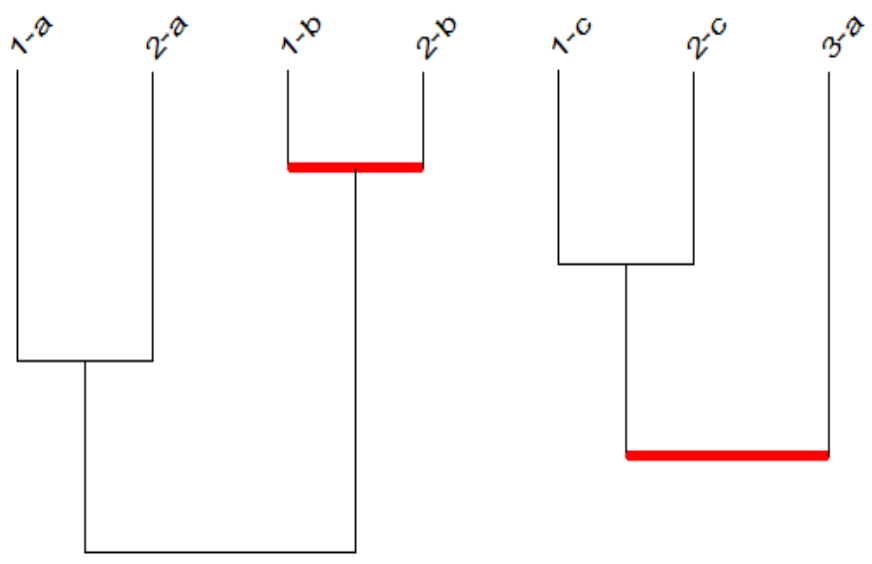

Figura 3. Árvore de similaridades do final do curso.

Nível: 1 : (1-b 2-b) similaridade : 1

Nível: 2 : (1-c 2-c) similaridade : 0.999999

Nível: 3 : (1-a 2-a) similaridade : 0.915288 
O primeiro bloco do 'ramo' mostra que as pseudonecessidades e pseudoimpossibilidades (2a) estão relacionadas com conhecimentos e experiências prévias que as alunas-professoras haviam elaborado, e estas mostram-se associadas com as postagens descritivas (1a). Essa relação sugere que não conseguiria dizer o que aprendeu e que nem conseguiria dar conta das demandas do curso, que, aliadas às dificuldades de tempo, são entendidas pelas alunas como impossibilitadoras de uma maior dedicação ao curso. É possível inferir que por falta de tempo para investir em pesquisa, o sujeito expresse suas crenças e opiniões em detrimento da elaboração de uma reflexão sobre a sua aprendizagem.

As relações de similaridade entre as postagens interpretativas e a formação de copossíveis são confirmadas ao longo de todo curso. A relação de similaridade mais significativa se dá entre as postagens reconstrutivas (1c) e a expansão da capacidade reflexiva dos sujeitos dadas pela construção de novos possíveis pedagógicos (2c).

As relações entre as postagens interpretativas com copossíveis (1b 1c), e das postagens reconstrutivas com os possíveis (1c 2c), já observados ao longo do curso, reafirmam que o pensamento reflexivo pode ser abordado, conforme proposto por Piaget (1985), em termos de um processo de construção de novidades ou possíveis cognitivos, de modo que, o desenvolvimento do pensamento reflexivo pressupõe uma ideia de construção pelo sujeito.

\section{Considerações Finais}

As análises realizadas atestam um processo de formação do professor reflexivo com o suporte das tecnologias digitais, que iniciou com a predominância das postagens que evidenciaram as pseudoimpossibilidades como obstáculos para a reflexão, o que foi superado, gradativamente, pela construção de novos possíveis. Essa evolução foi evidenciada por descrições objetivas e, posteriormente, por postagens interpretativas e reconstrutivas. As alunas-professoras, nesse processo, construíram novas concepções e reconstruíram práticas pedagógicas que, antes do processo reflexivo construído ao longo do curso, não eram consideradas "possíveis".

Nos portfólios das alunas-professoras foi possível observar que as tecnologias cumpriram um papel fundamental, tanto na constituição do "ser aluna" quanto na reconstrução do "ser professora". Se no início do curso as tecnologias mostraram-se como obstáculos às ações, essas se tornaram grandes aliadas na medida da sua superação, ampliando as possibilidades de aprendizagem e inovações.

Identificou-se, mediante as reflexões das professoras-alunas, que o portfólio de aprendizagem se constituiu em um potencializador da criação de novas formas de pensar e articular teorias e práticas, construídas nas interações com os objetos de conhecimento disponíveis na web e com os sujeitos envolvidos na rede de formação.

Cabe destacar que redes dessa natureza não se viabilizam sem a disponibilidade de um sistema de comunicação que possibilite as publicações em broadcasting (um para todos) e os diálogos em tempo real.

Agradecimento: O presente trabalho foi realizado com apoio da Coordenação de Aperfeiçoamento de Pessoal de Nível Superior - Brasil (CAPES) - Código de Financiamento 001". 
VIII Congresso Brasileiro de Informática na Educação (CBIE 2019)

Anais dos Workshops do VIII Congresso Brasileiro de Informática na Educação (WCBIE 2019)

\section{Referências}

Alarcão, I. (Org). (1996) "Formação reflexiva de professores: estratégias de supervisão", Editora Porto, (Coleção CIDIne).

Aragón, R; Charczuk, S. B and Ziede, M. (2016) "Uma arquitetura pedagógica na elaboração de histórias coletivas", Anais dos Workshops do Congresso Brasileiro de Informática na Educação, [S.1.], p. 569, nov. ISSN 2316-8889. Disponível em: <https://www.brie.org/pub/index.php/wcbie/article/view/6979>. Acesso em: 15 set. 2019. doi:http://dx.doi.org/10.5753/cbie.wcbie.2016.569.

Brasil. Instituto Nacional de Estudos e Pesquisas Educacionais Anísio Teixeira (Inep) (2015) "Censo da educação superior 2015: resumo técnico", Brasília: Inep, 2015. Disponível em: $<\mathrm{http}: / /$

download.inep.gov.br/download/superior/censo/2015/resumo_tecnico_censo_educacao_ superior_2015.pdf>. Acesso em: 05 set. 2018.

Costa, I.T.; Magdalena, B. C and Fagundes, L.C. (2005) "Weblog: considerações sobre sua arquitetura e uso pedagógico", In: Anais do SBIE XVI Simpósio Brasileiro de Informática na Educação. Juiz de Fora, Minas Gerais.

Flick, U. (2009) “Desenho na pesquisa qualitativa”, Porto Alegre, Editora Artmed, (Coleção Pesquisa qualitativa).

Grás, R. (1992) “L’analyses des donnés: une méthodologie de traitement de questions de didactique", Recherches en Didactiques Mathématiques, vol 12-1.

Nevado. R. A.; Carvalho, M. J. S. and Menezes, C. S. (Org.). (2007) "Aprendizagem em Rede na Educação a Distância" Estudos e Recursos para Formação de Professores. Porto Alegre: Ricardo Lenz.

Nóvoa, A. (2017) "Firmar a posição como Professor: afirmar a profissão docente", In: Cadernos de Pesquisa v.47 n.166 p.1106-1133 out./dez.

Piaget, J. (1985) "O possível e o Necessário: evolução dos possíveis na criança”, Porto Alegre, Artes Médicas, vol. 1.

Turchielo, L. B. (2017) "A Formação de professores reflexivos no curso de Pedagogia a distância da UFRGS: um estudo de caso", Tese (Doutorado em Educação). Faculdade de Educação. Universidade Federal do Rio Grande do Sul, Porto Alegre -RS.

Vieira Junior, R. R. M and Reategui, E. B (2018) "Arquitetura Pedagógica para leitura de textos digitais", Anais dos Workshops do Congresso Brasileiro de Informática na Educação, [S.1.], p. 876, out. (2018). ISSN 2316-8889. Disponível em: <https://www.brie.org/pub/index.php/wcbie/article/view/8313>. Acesso em: 17 set. 2019. doi:http://dx.doi.org/10.5753/cbie.wcbie.2018.876.

Zeichner, K. and Liston, D. (2014) Reflective teaching: An introduction, New York: Routledge, (2nd edition). 